\title{
MicroRNA-203 induces apoptosis by upregulating Puma expression in colon and lung cancer cells
}

\author{
NAOTAKE FUNAMIZU ${ }^{1}$, CURTIS R. LACY ${ }^{2}$, MINORI KAMADA ${ }^{3}$, \\ KATSUHIKO YANAGA $^{1}$ and YOSHINOBU MANOME ${ }^{3}$
}

\begin{abstract}
${ }^{1}$ Department of Surgery, The Jikei University School of Medicine, Tokyo, Japan; ${ }^{2}$ Howard University School of Medicine, Washington, DC, USA; ${ }^{3}$ Department of Molecular Cell Biology, The Jikei University School of Medicine, Tokyo, Japan
\end{abstract}

Received August 11, 2015; Accepted September 4, 2015

DOI: $10.3892 /$ ijo.2015.3178

\begin{abstract}
The present study investigated the relationship between microRNA-203 (miR-203) and the p53 upregulated modulator of apoptosis (Puma) in colon (HCT116) and lung cancer (A549) cells. Colon and lung cancer cell lines were selected for this study since a relationship between p53/miR-203 and p53/Puma has been established in both cancers. In the present study, adriamycin and nutlin-3 were used to activate p53, which induced both miR-203 and Puma expression in HCT116 cells. In contrast, HCT 116 cells with downregulated p53 showed decreased miR-203 and Puma expression. Importantly, we found that overexpressed miR-203 in HCT116 cells resulted in significantly increased Puma expression $(\mathrm{P}<0.05)$. Based on these findings, we hypothesized that another limb of the p53/Puma axis depends on miR-203 expression. To further validate this relationship, we used lung cancer cells (A549) and found that activated p53 increased both miR-203 and Puma expression. In addition, we found that Puma expression remained elevated in cells with overexpressed miR-203 in the presence of p53 downregulation. Cumulatively, our data purport that p53 not only increased Puma expression directly, but that it may also do so through miR-203. Additionally, functional studies revealed that miR-203 overexpression induced apoptosis and inhibited cell invasiveness.
\end{abstract}

\section{Introduction}

MicroRNAs (miRNAs) are small non-coding RNA molecules that are highly conserved throughout eukaryotic organisms. Before miRNAs become functionally active, they must undergo a series of post-transcriptional modifications. Mature single-stranded miRNAs downregulate gene translation,

Correspondence to: Dr Naotake Funamizu, Department of Surgery, The Jikei University School of Medicine, 3-25-8 Nishi-shinbashi, Minato-ku, Tokyo 105-8461, Japan

E-mail: funamizujikei@yahoo.co.jp

Key words: microRNA-203, Puma, gemcitabine sensitivity or mediate mRNA cleavage by utilizing partial sequence homology bind to targets in the $3^{\prime}$-untranslated region (3'-UTR) (1). Surprisingly, miRNAs also have the potential to suppress several target genes simultaneously (2). Similarly, numerous miRNAs play important roles as either oncogenes or tumor suppressor genes, and are involved in a variety of cellular processes including proliferation, apoptosis, tumorigenesis, and chemoresistance (3-5). Furthermore, several studies have shown that dysregulated miRNA expression is frequently found in various human cancers (6-9). More specifically, microRNA-203 (miR-203) has been found to regulate the suppressor of cytokine signaling 3 (SOCS3), which is involved in the negative-feedback regulation of JAK/STAT signal transduction (10). Additionally, there are some evidence that miR-203 is regulated by p53, while Nakano and Vousden (11) identified the novel gene Puma as a target for activation of p53. Currently, it is believed that Puma plays a role in p53-mediated apoptosis through the cytochrome-c/Apaf-1-dependent pathway (11). In the present study, we sought to investigate the tripartite relationship between miR-203, p53, and Puma in cancer cells (Fig. 1). We found that overexpressed miR-203 in HCT116 and A549 cells caused increased Puma expression and improved gemcitabine sensitivity. In addition, we found that activated p53 induced miR-203 and Puma expression, while downregulated p53 resulted in decreased expression levels of miR-203. These findings imply that miR-203 may have a variety of roles, including a tumor suppressor gene, a predictive marker of tumor response to chemotherapy, and therapeutic value as a potential target.

\section{Materials and methods}

Cell lines and culture conditions. Human colon cancer (HCT116) and lung cancer (A549) cell lines were cultured in Dulbecco's modified Eagle's medium (DMEM; Invitrogen, Carlsbad, CA, USA) with $10 \%$ fetal bovine serum (FBS), $100 \mu \mathrm{g} / \mathrm{ml}$ of streptomycin, and $100 \mathrm{U} / \mathrm{ml}$ of penicillin at $37^{\circ} \mathrm{C}$ in a humidified chamber supplemented with $5 \% \mathrm{CO}_{2}$.

Oligonucleotides. Precursors of miR-203, its inhibitor, and its negative controls were purchased from Ambion (Tokyo, Japan). P53-shRNAs and their negative controls were purchased from Invitrogen (Tokyo, Japan). 
Pre-miR-203 transfection experiments. miR-203, its inhibitor, and respective controls were transfected using RNAiMAX transfection reagent (Invitrogen). Transfection efficiency was determined using quantitative real-time polymerase chain reaction (PCR). A549 and HCT116 cells were transfected with $50 \mathrm{nM}$ of miRNA in a 6-well plate for RNA extraction, or $10-\mathrm{cm}$ dishes for further studies including proliferation, and gemcitabine sensitivity assays following the previously reported protocol (13). RNA was isolated $48 \mathrm{~h}$ after transfection to measure miR-203 and Puma expression. Cells from $10-\mathrm{cm}$ dishes were transferred $12 \mathrm{~h}$ after transfection to 96-well plates for proliferation, drug sensitivity, and apoptosis assays, and 24-well plates for invasion assays. All transfection experiments were independently repeated three times.

RNA preparation and real-time PCR analysis. Total cellular RNA was extracted from cells cultured in 6-well plates using TRIzol (Invitrogen). Cell pellets were suspended in an aliquot of $1 \mathrm{ml} /$ well according to the manufacturer's recommendations. Isolated RNA ( $6 \mu \mathrm{g})$ was combined with random primers (6-mer) for reverse transcription (GE Healthcare, Buckinghamshire, UK) following the manufacturer's instructions. Gene expression levels were measured using TaqMan real-time PCR (Applied Biosystems Life Technologies, Foster City, CA, USA) containing probes for 4 genes: Puma (ID: Hs00248075_m1), BAX (ID: Hs00180269_m1, TP53 (ID: Hs00153349_m1), and miR-203 (ID: 000507), with GAPDH (ID: Hs99999905_m1) and RNAU6 (ID: 001002) as internal controls for genes and miRs, respectively. Gene expression levels were calculated using the relative quantification $\Delta \Delta \mathrm{Ct}$ method as we reported previously (13). Each sample was assayed in triplicates.

Western blot analysis. In order to evaluate whether miR-203 affected Puma expression at the protein level, a western blot analysis was performed as previously reported (14). At $24 \mathrm{~h}$ after adding adriamycin or nutlin-3, and DMSO as a control, protein was extracted from cell pellets using RIPA buffer with protease inhibitor (Invitrogen). Protein concentration was measured using Bio-Rad protein assay solution. Equal amounts of total protein were separated using SDS-PAGE gels under reducing conditions. The protein was then transferred to a polyvinylidene difluoride (PVDF) membrane (Invitrogen) before being blocked with 5\% non-fat milk in TBS-Tween. The membrane was then incubated with primary antibodies against p53, Puma (Santa Cruz Biotechnology, Inc., Santa Cruz, CA, USA) and $\beta$-actin (Cell Signaling Technology, Inc., Tokyo, Japan) at a dilution of 1:1,000. The appropriate primary antibodies were followed by horseradish peroxidase (HRP) conjugated secondary antibodies (Amersham Pharmacia Biotech, Piscataway, NJ, USA) at a dilution of 1:10,000. Visualization was achieved using SuperSignal West chemiluminescent solution (Pierce Biotechnology, Inc., Rockford, IL, USA).

Transient transfection of p53-shRNA. To knock down endogenous p53, A549 cells were seeded in 6-well plates at 70-80\% confluency. P53-shRNA and its negative control-shRNA were transfected at a final concentration of $100 \mathrm{nM}$ using Lipofectamine RNAiMAX reagent (Invitrogen), and cultured

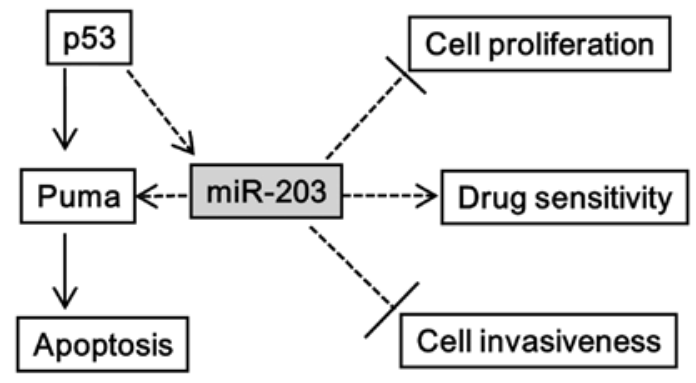

Figure 1. A putative pathway for the association between miR-203 and the p53/Puma axis. The proposed pathway demonstrates that miR-203 may control Puma expression. Increased levels of miR-203 by activated p53 lead to increased Puma expression.

for $48 \mathrm{~h}$ using a previously published protocol (15). shRNA suppression efficiency was determined using real-time PCR analysis, and repeated at least three times.

Gemcitabine sensitivity assay with transfection of miR-203 or miR-203 inhibitor. A drug sensitivity assay was performed as described in our previous study (16). HCT116 or A549 cells were seeded in $10-\mathrm{cm}$ dishes at $70 \%$ confluency, and cultured for $12 \mathrm{~h}$. miR-203, its inhibitor, and the appropriate controls were then transfected in each dish and cultured overnight. Transfected cells were then seeded in 96-well plates at 4,000 cells/well in triplicates, and incubated for $12 \mathrm{~h}$. Cells were then treating with stepwise, 4 -fold serial dilutions of gemcitabine (from $100 \mu \mathrm{M}$ ) and incubated for $96 \mathrm{~h}$. To evaluate cell viability, cells were fixed with $25 \%$ glutaraldehyde for $30 \mathrm{~min}$ at room temperature, and then stained with $200 \mu \mathrm{l}$ of $0.05 \%$ methylene blue for $20 \mathrm{~min}$. The dye was eluted with $0.33 \mathrm{M} \mathrm{HCl}$ while agitating for $20 \mathrm{~min}$. Absorbance was measured using a microplate reader (model 3550; Bio-Rad, Tokyo, Japan) at $598 \mathrm{~nm}$. The $50 \%$ inhibitory concentration $\left(\mathrm{IC}_{50}\right)$ for cell growth was then calculated.

Cell proliferation assay with transfected miR-203 or control. To investigate the miR-203 effect on cell proliferation, growth rates of HCT116 and A549 cells transfected with miR-203 or a control were compared. Growth for both cell lines was carried out using the colorimetric methylene blue assay in 96-well plates at a density of 4,000 cells/well. The first $12 \mathrm{~h}$ post-transfection was considered day 0 . Mean values were calculated from three different wells in triplicate for four days.

Apoptosis assay. To evaluate whether miR-203 induces caspase-3/7 through the upregulation of Puma, A549 cells were cultured for $12 \mathrm{~h}$ in 96-well plates in triplicate, and treated with $50 \mathrm{nM}$ of miR-203, or $50 \mathrm{nM}$ of miR-203 inhibitor or their respective controls. The assay was analyzed using a caspase-3/7 assay kit (Promega, Tokyo, Japan) according to the manufacturer's instructions.

Matrigel cell invasion assay with transfection of miR-203 or $m i R-203$ inhibitor. An invasion assay was performed in 24-well BioCoat Matrigel invasion chambers (Becton-Dickinson, San Diego, CA, USA) following the manufacturer's instructions. A549 cells in $10-\mathrm{cm}$ dishes were cultured for $12 \mathrm{~h}$ after being transfected with miR-203, its inhibitor, or their 

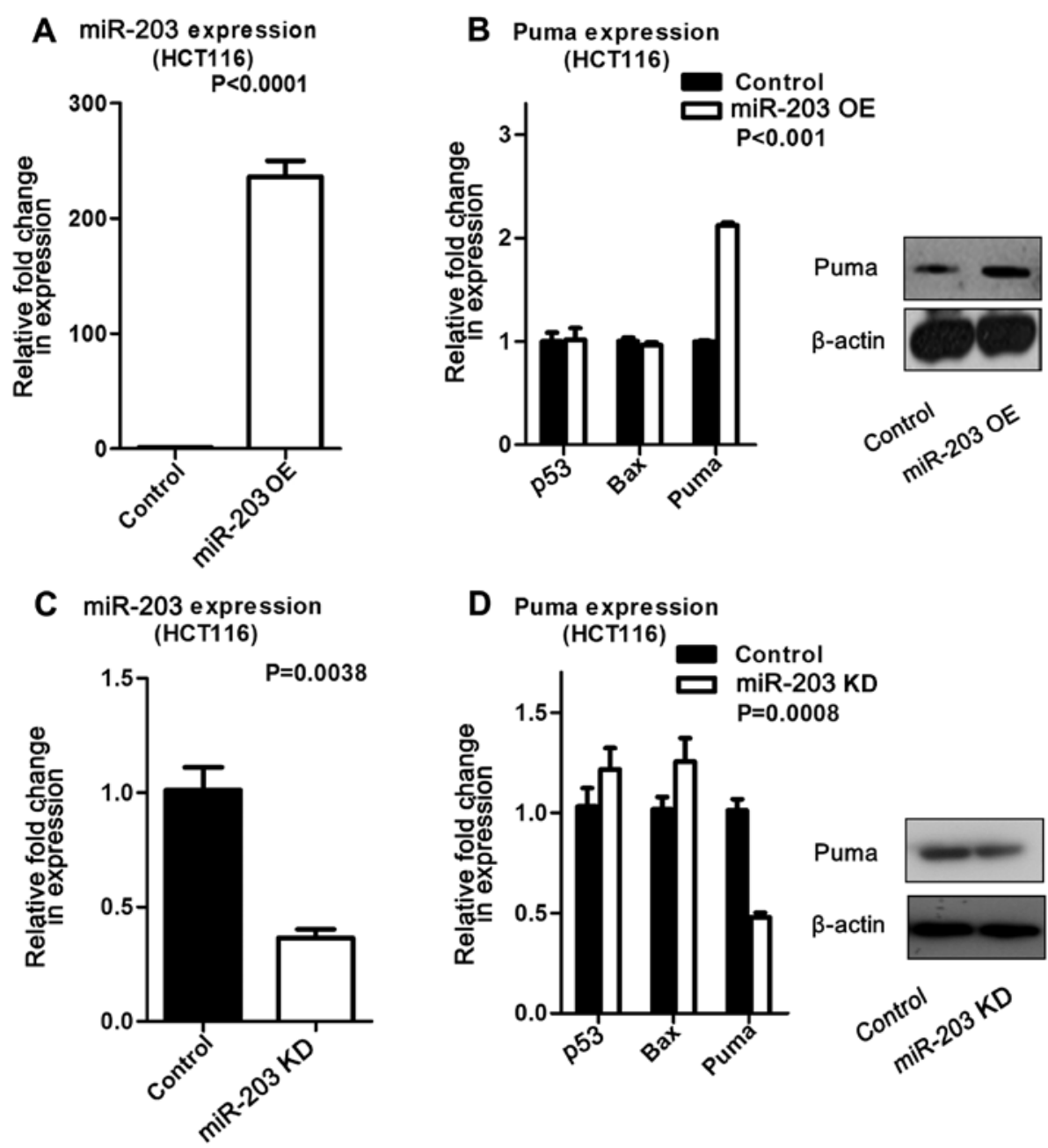

Figure 2. The functional analysis of miR-203 in colon cancer cells. (A) miR-203 (miR-203 OE) was transfected in HCT116 cells. Transfection efficiency was determined by real-time PCR and is displayed as a relative fold-change. Data represent the mean of triplicates from three independent experiments. (B) Cells transfected with miR-203 (miR-203 OE) showed increased Puma expression at mRNA and protein levels in both cell lines. (C) Efficacy of the miR-203 inhibitor (miR-203 KD) was confirmed by real-time PCR. (D) Downregulated miR-203 (miR-203 KD) resulted in decreased Puma expression.

negative controls. Cells were then harvested and seeded in Matrigel-coated $\left(4 \times 10^{4}\right.$ cells/well) and control-insert wells $\left(4 \times 10^{4}\right.$ cells/well) before being incubated for $20 \mathrm{~h}$. Cells that penetrated the chamber membranes were considered invasive, and fixed with methanol for 5 min before being stained with crystal violet for $5 \mathrm{~min}$. Cells were observed under a microscope (x20 magnification) and counted in 3 random fields. All assays were performed in triplicates.

Statistical analysis. All results were performed in triplicate and repeated at least two times. Data are shown as the mean \pm SD where applicable. Graphpad Prism v5.0 (GraphPad Software, Inc., La Jolla, CA, USA) was used for all statistical analyses. Levels of significance for comparison between cell lines were determined by the Student's t-test distribution. A $\mathrm{P}$-value of $<0.05$ was considered statistically significant.

\section{Results}

miR-203 expression is correlated with Puma expression. Upregulated miR-203 in HCT116 cells increased Puma expression at both the mRNA and protein levels compared to its control. In contrast, miR-203 suppression resulted in decreased Puma expression at the mRNA and protein levels (Fig. 2). The same experiments were repeated in A549 cells, and found to produce the same trend (Fig. 3). These data suggested that miR-203 induced Puma expression. In addition, we measured Bax expression by real-time PCR, but did not find the expression pattern described in other studies (data not shown).

P53 activation was associated with miR-203 and Puma expression in HCT116 and A549 cells. Further studies revealed that activated p53 increased miR-203 and Puma expression in HCT116 cells compared to the control (Fig. 4). Moreover, this finding was validated at both the mRNA and protein levels in A549 cells (Fig. 5A). On the other hand, suppressing p53 significantly reduced miR-203 and Puma expression in A549 cells (Fig. 5B), suggesting that miR-203 expression is influenced by activated p53. To determine whether the miR-203 effect on Puma is facilitated by p53, miR-203 was overexpressed in A549 cells with downregulated p53. This study revealed that Puma levels were increased at both the mRNA and protein levels (Fig. 6). In addition, miR-203 levels were measured following addition of adriamycin or nutlin-3 to 

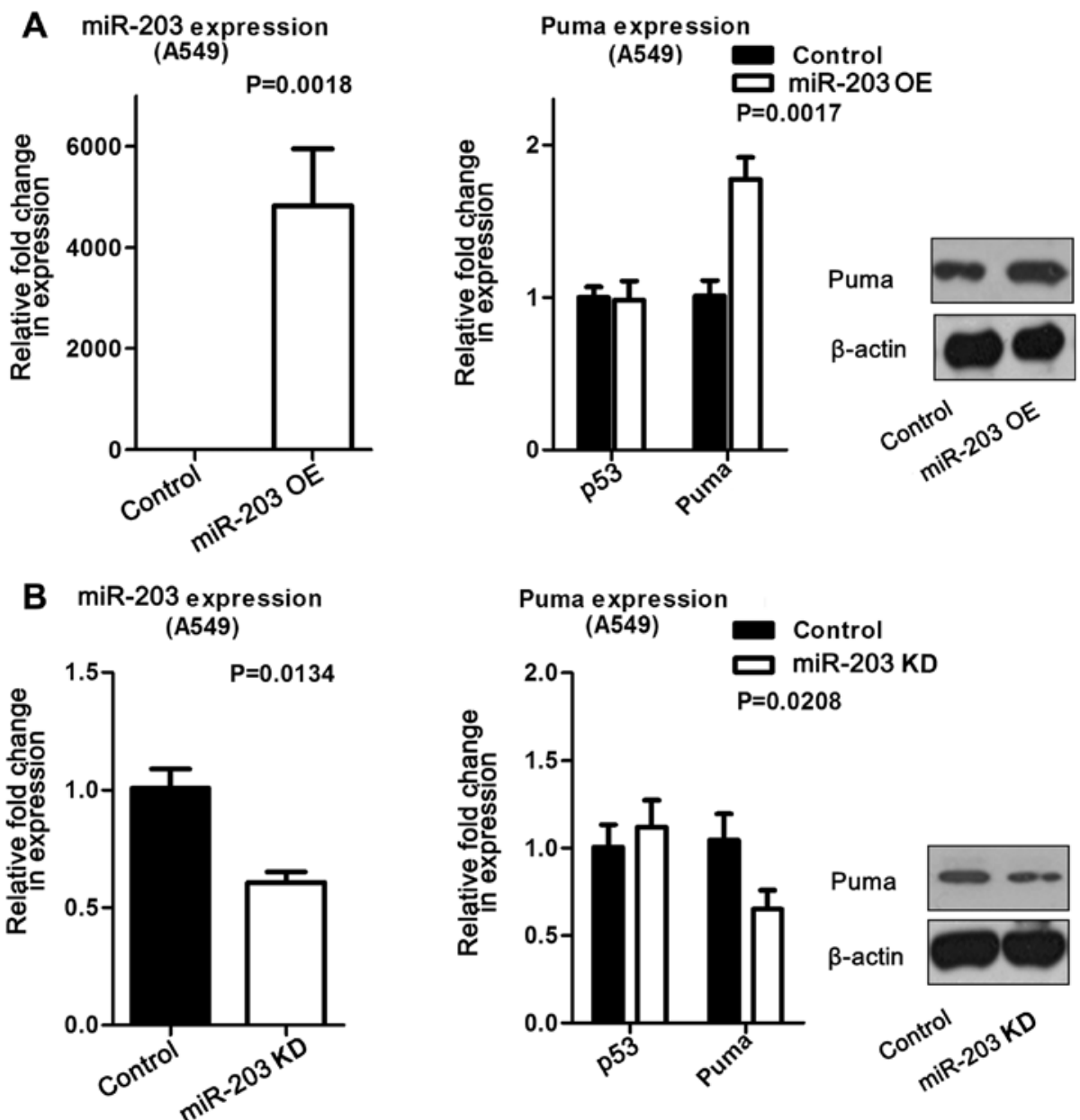

Figure 3. A validation study for the association between miR-203 and Puma in A549 cells. (A) miR-203 (miR-203 OE) or its control was transfected at $50 \mathrm{nM}$ for real-time PCR. Transfected cells showed increased Puma expression at both mRNA and protein levels. All quantitative values are the mean \pm SD.

(B) miR-203 inhibition (miR-203 KD) decreased mRNA and protein levels of Puma in A549 lung carcinoma cells.
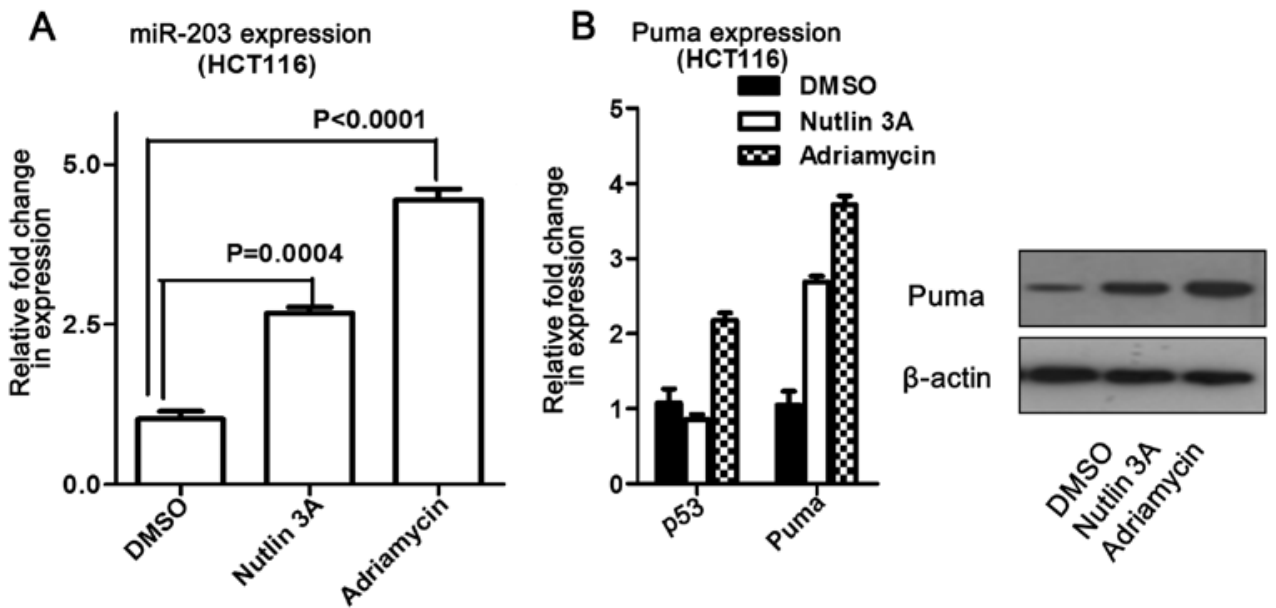

Figure 4. Activated p53 induced miR-203 expression in colon cancer cells. (A) P53 activation by adriamycin or nutlin-3A significantly increased miR-203 expression in HCT116 cells. (B) Activated p53 induced Puma expression at the mRNA and protein levels. Real-time PCR data represent the mean of three biological replicates. Immunostaining is representative of two independent experiments.

p53-knockout cells (A549). The results showed that miR-203 levels did not change compared to the control, but that Puma expression significantly increased (Fig. 6). Overall, these data suggest that miR-203 may induce Puma expression without p53 influence.
miR-203 increases gemcitabine sensitivity while inhibiting cell proliferation in HCT116 and A549 cells. To evaluate the functional role of miR-203 in colon and lung carcinoma cells, pre-miR-203 or its inhibitor was transfected in HCT116 and A549 cells using Lipofectamine. We found that overexpressed 


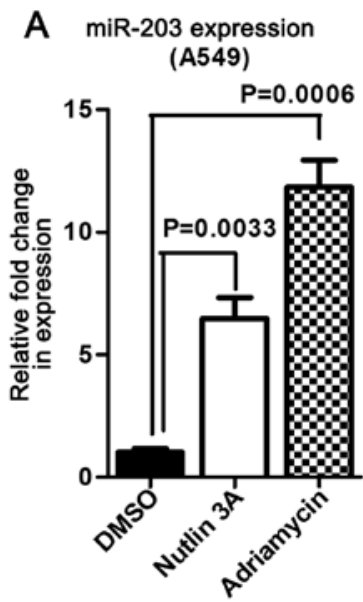

B

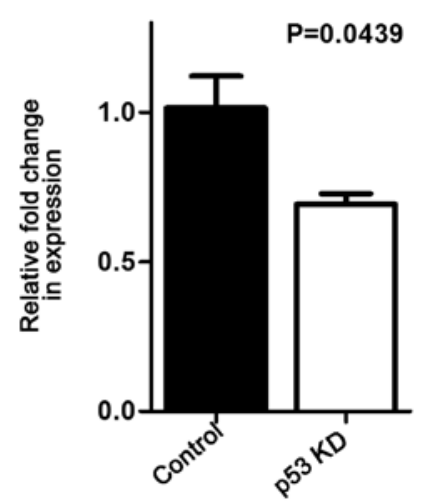

Puma expression

(A549)

DMSO

Nutlin 3A

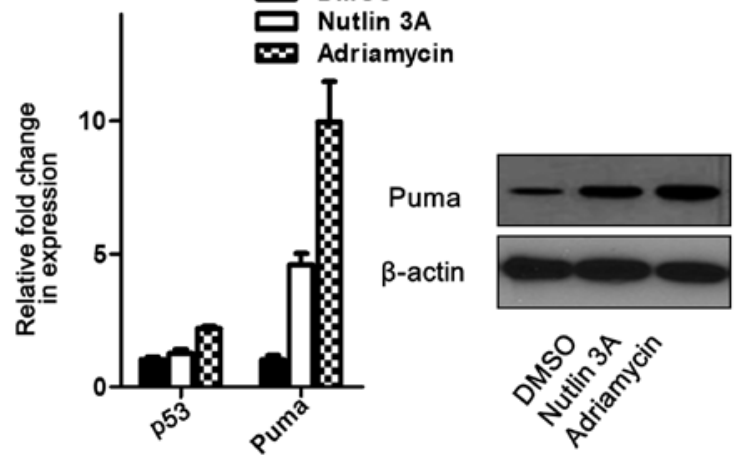

Puma expression

(A549)

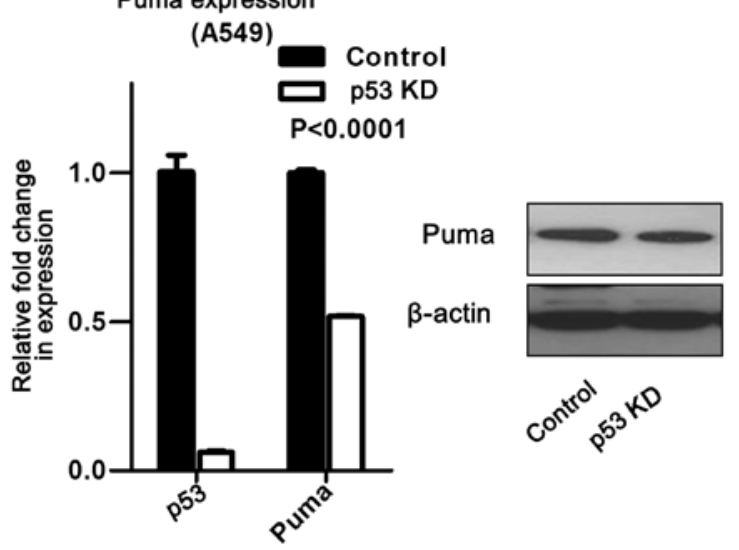

Figure 5. miR-203 and Puma expression in p53-regulated lung cancer cells. (A) Activated p53 upregulated miR-203 and Puma expression. (B) Inhibited p53 reduced miR-203 and Puma expression.

miR-203 increased gemcitabine sensitivity and decreased proliferation in both cell lines (Fig. 7). In contrast, downregulated miR-203 did not show any significant difference in gemcitabine sensitivity or cell proliferation (data not shown). These data suggest that increased miR-203 played an essential role in decreasing chemoresistance.

Overexpressed miR-203 induces apoptosis and decreases cell invasiveness. To examine whether increased Puma expression by miR-203 induces apoptosis, an apoptosis assay was performed. Increased miR-203 resulted in increased apoptosis, while miR-203 inhibition did not affect apoptosis compared to the control (Fig. 8A). Similarly, overexpressed miR-203 decreased the invasive potential of A549 cells, while downregulated miR-203 had no effect on invasiveness (Fig. 8B).

\section{Discussion}

Dysregulated miRNA expression is responsible for the initiation and progression of several types of human cancers. Recent evidence has demonstrated that aberrant miRNA expression affects cell proliferation, invasion, apoptosis, and chemosensitivity (17-19). Among these miRNAs, miR-203 remains an important subject of investigation since its role as a tumor suppressor gene or oncogene remains largely undetermined. $\mathrm{Bu}$ and Yang reported that miR-203 is significantly downregulated in malignant melanoma and that it targets versican (20).
In addition, Tian et al found that miR-203 levels were significantly lower in squamous cell carcinoma of the larynx compared to the normal surrounding tissue (21). Moreover, Feber et al revealed that miR-203 expression is decreased in esophageal cancer (22), while Wei et al showed similar results in hepatocellular carcinoma (23). In contrast, several studies have found that miR-203 is upregulated in a number of malignancies, including colon cancer, breast cancer, and transitional cell carcinoma of the bladder (24-26). Furthermore, in pancreatic ductal adenocarcinoma, two studies showed that miR-203 is overexpressed and that it is associated with a poorer prognosis $(27,28)$. These two studies also suggested that miR-203 may be a novel prognostic marker for patients with pancreatic cancer. Despite the discrepancies between the miR-203 expression and various malignancies, many studies have considered miR-203 to function as a tumor suppressor gene rather than an oncogene. Additionally, numerous studies have suggested that miR-203 promotes tumorigenesis through its interaction with p53. Likewise, it is well known that miR-203 promotes keratinocyte proliferation and differentiation by targeting p63, a member of the p53 family (29-34). For instance, McKenna et al showed that p53 induces miR-203 in keratinocytes of human foreskin (12). Additionally, p53 has been shown to regulate miR-203 expression in colon cancer cells (35). On the other hand, p53 is a known transcriptional activator of an array of genes that induce apoptosis. One of these genes, named Puma (p53 upregulated modulator of apoptosis), was recently 
A miR-203 expression

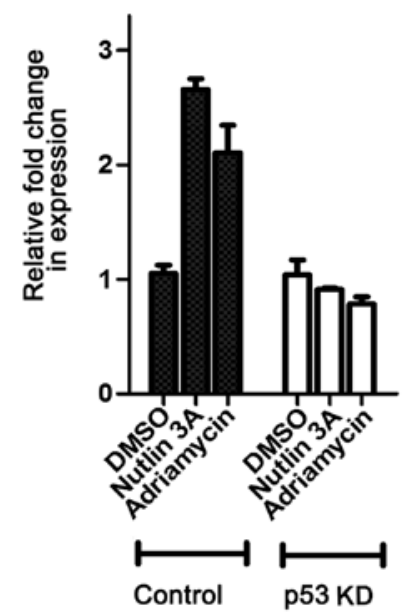

B

Puma expression (p53 inhibited A549)
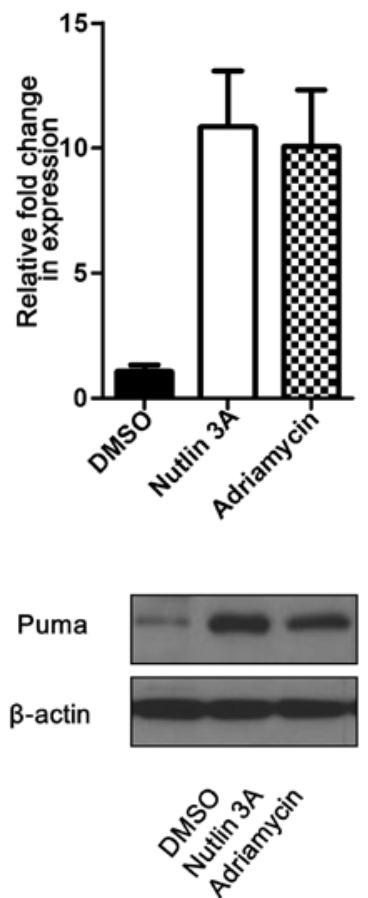

C Puma expression

(p53 inhibited A549)

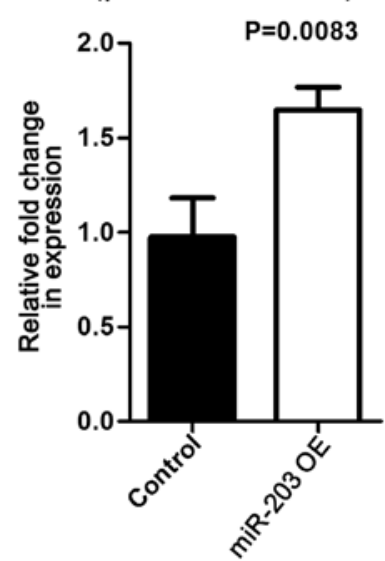

Puma

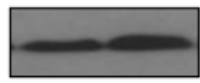

$\beta$-actin

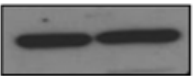

Figure 6. Puma levels relative to miR-203 overexpression in A549 cells with downregulated p53. P53 activators (nutlin3A/adriamycin) were not involved in miR-203 expression in p53-knockdown cells. In spite of p53 inhibition, p53 activators still resulted in higher levels of Puma expression. Overexpressed miR-203 resulted in higher levels of Puma expression in p53-knockdown cells.
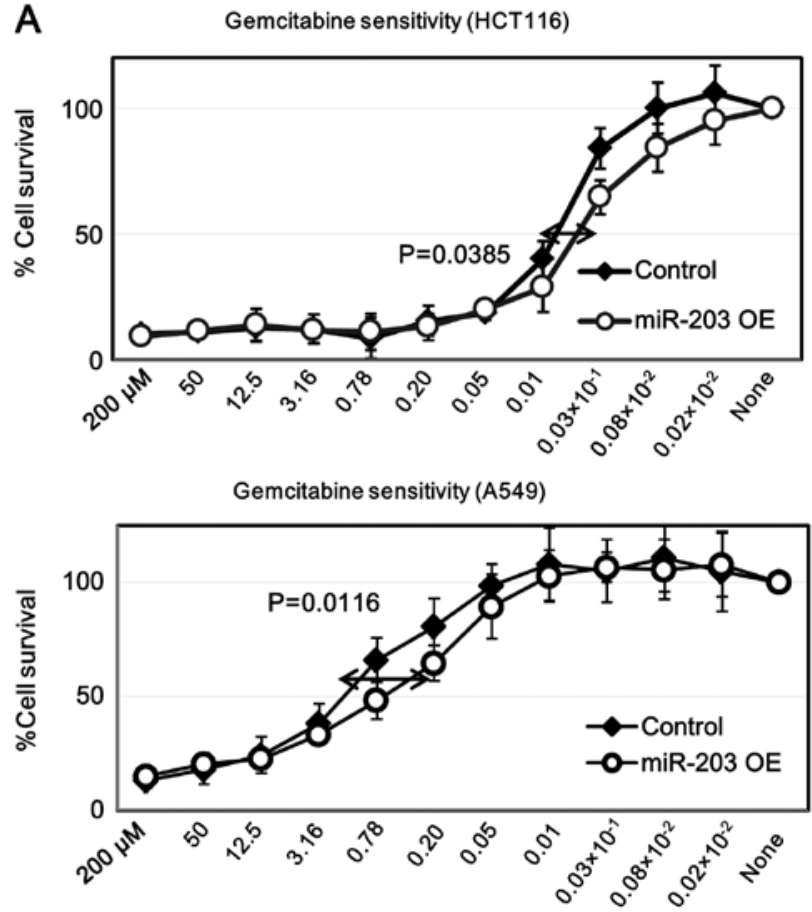

B Proliferation(HCT116)

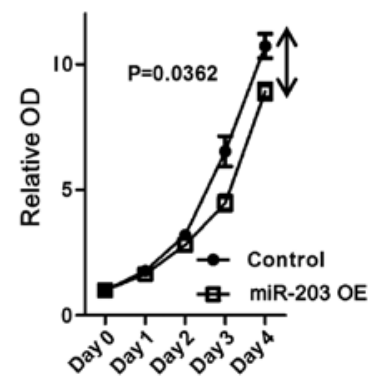

Proliferation(A549)

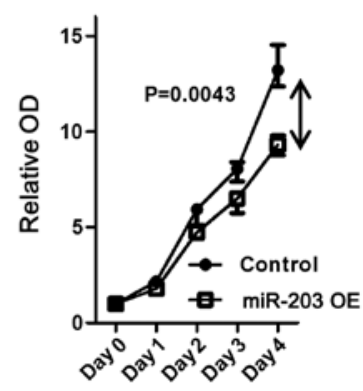

Figure 7. A functional study of the miR-203 effect on chemoresistance and cell proliferation. (A) A gemcitabine sensitivity assay was performed by colorimetric assay at the $\mathrm{IC}_{50}$ of cells transfected with miR-203 (miR-203 OE), miR-203 inhibitor (miR-203 KD), and the respective control for $96 \mathrm{~h}$. miR-203 OE improved gemcitabine sensitivity in both cell lines. (B) miR-203 significantly reduced cell proliferation by colorimetric assay in HCT116 and A549 cell lines as compared to the control. Values are the mean of three independent experiments performed in triplicate. The error bar is presented as the SD. Data on day 4 were used for the statistical analysis.

identified by Nakano and Vousden as a 'BH3-only' member of the Bcl2 family (11). Furthermore, Hemann et al (36) and
Michalak et al (37) reported that the downregulation of Puma effectively suppresses p53-dependent apoptosis. Based on data 
A

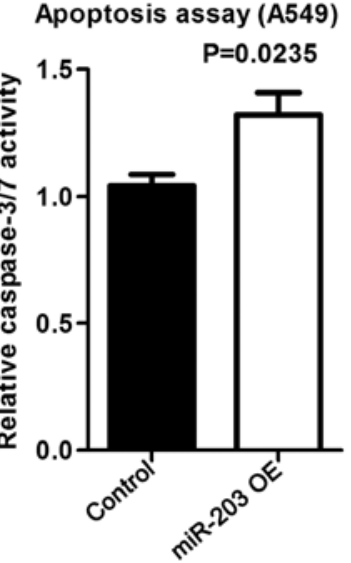

B

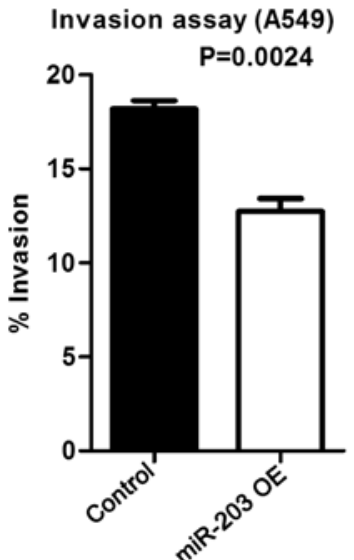

Apoptosis assay (A549)

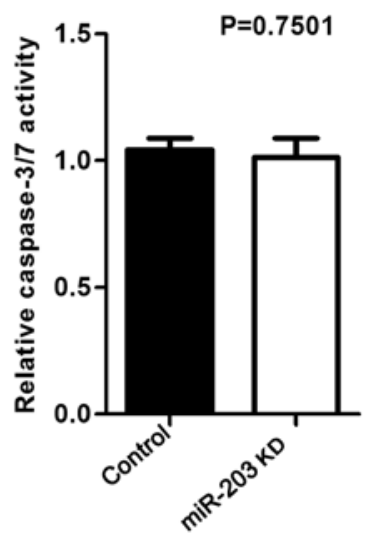

Invasion assay (A549) $P=0.0617$

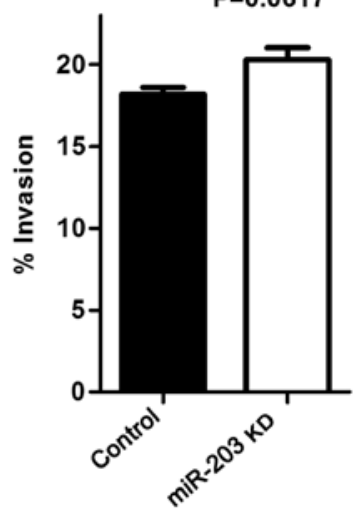

Figure 8. Further studies of the miR-203 effect on cell invasion and apoptosis. (A) A549 cells were seeded in 96-well plates after being transfected overnight with $50 \mathrm{nM}$ of miR-203 (miR-203 OE) or miR-203 inhibitor (miR-203 KD), and their controls. miR-203 OE contributed to the induction of apoptosis. Successful induction of apoptosis was assessed by measuring caspase-3/7 activity. Data represent the mean of three replicates \pm SD. (B) After transfecting $50 \mathrm{nM}$ of miR-203 (miR-203 OE) or miR-203 inhibitor (miR-203 KD), and their controls, cells were seeded in Matrigelcoated chambers for invasion assays. miR-203 OE significantly reduced cell invasiveness. Stained cells were counted in 3 separate microscopic fields per well. The values were then averaged, and the mean \pm SD was calculated from triplicates.

collected, we hypothesized that miR-203 indirectly regulates Puma expression regardless of p53 activity (Fig. 1). Our data revealed that increased or decreased miR-203 expression correlated positively with Puma expression, and that activated p53 increased both miR-203 and Puma expression. In relation to this finding, we also found that shRNA-mediated inhibition of $\mathrm{p} 53$ resulted in decreased expression of both miR-203 and Puma. Collectively, our findings support the idea that miR-203 may be a mediator of the p53-Puma pathway. In addition, we demonstrated that overexpressed miR-203 improved gemcitabine sensitivity; a finding consistent with other data which showed that miR-203 inhibits cell proliferation and invasiveness in prostate carcinoma, and induces apoptosis in transitional cell carcinom (38). Moreover, Feber et al revealed that miR-203 suppresses cell proliferation in esophageal carcinoma (22), while Miao et al showed that miR-203 inhibits cell migration, invasion, and the epithelial-mesenchymal transition (EMT) via caveolin-1

in pancreatic carcinoma (39). Considering these data, our results support the hypothesis that miR-203 acts as a tumor suppressor gene by regulating Puma expression in both colon and lung cancer cells. However, Li et al (40) reported that p53 negatively regulates the miR-203 function when they found that overexpressed miR-203 decreases chemoresistance in p53-mutated colon cancer cells, but has no effect on p53 wild-type cells. In contrast, Li et al supported our findings by showing that overexpressed miR-203 decreases levels of blc-xL (an anti-apoptotic gene), but increases levels of Bax (a pro-apoptotic gene) (40). Clinical data have shown that patients with wild-type p53 colorectal cancer undergoing chemotherapy have significantly better survival than those with mutated p53 (41). The uncertainty of miR-203 function may be due to its targeted activity against numerous molecules involved in a variety of cellular functions. Some of its targets include p63, Akt2, BMI1, and LASP1 which are responsible for cellular proliferation, apoptosis, and chemoresistance (40-46). Even though our results are consistent with previously published data, we acknowledged that our study has some limitations. The most important limitation is the lack of an elucidated pathway through which miR-203 regulates Puma expression. The second limitation is that we do not have a mouse model or clinical data to validate our findings. In conclusion, we have shown that miR-203 expression was affected by $\mathrm{p} 53$ activation, and that miR-203 might function as a tumor suppressor gene by regulating Puma expression. Our data also indicated that increased miR-203 was involved in increased gemcitabine sensitivity and decreased cell proliferation in both colon and lung cancer cells. Overall, we believe that our data further support the importance of understanding patient's genetic profiles in order to develop more effective patient-specific therapies, which can lead to improved survival rates and quality of life.

\section{References}

1. Bartel DP: MicroRNAs: Genomics, biogenesis, mechanism, and function. Cell 116: 281-297, 2004.

2. Lewis BP, Burge CB and Bartel DP: Conserved seed pairing, often flanked by adenosines, indicates that thousands of human genes are microRNA targets. Cell 120: 15-20, 2005.

3. Li C, Hashimi SM, Good DA, Cao S, Duan W, Plummer PN, Mellick AS and Wei MQ: Apoptosis and microRNA aberrations in cancer. Clin Exp Pharmacol Physiol 39: 739-746, 2012.

4. Garofalo M, Romano G, Di Leva G, Nuovo G, Jeon YJ, Ngankeu A, Sun J, Lovat F, Alder H, Condorelli G, et al: EGFR and MET receptor tyrosine kinase-altered microRNA expression induces tumorigenesis and gefitinib resistance in lung cancers. Nat Med 18: 74-82, 2012.

5. Wu Y, Xiao Y, Ding X, Zhuo Y, Ren P, Zhou C and Zhou J: A miR-200b/200c/429-binding site polymorphism in the 3 ' untranslated region of the AP- $2 \alpha$ gene is associated with cisplatin resistance. PLoS One 6: e29043, 2011.

6. Kent OA and Mendell JT: A small piece in the cancer puzzle: microRNAs as tumor suppressors and oncogenes. Oncogene 25: 6188-6196, 2006.

7. Nikitina EG, Urazova LN and Stegny VN: MicroRNAs and human cancer. Exp Oncol 34: 2-8, 2012.

8. Iorio MV and Croce CM: MicroRNA dysregulation in cancer: Diagnostics, monitoring and therapeutics. A comprehensive review. EMBO Mol Med 4: 143-159, 2012

9. Piepoli A, Tavano F, Copetti M, Mazza T, Palumbo O, Panza A, di Mola FF, Pazienza V, Mazzoccoli G, Biscaglia G, et al: Mirna expression profiles identify drivers in colorectal and pancreatic cancers. PLoS One 7: e33663, 2012. 
10. Ru P, Steele R, Hsueh EC and Ray RB: Anti-miR-203 upregulates SOCS3 expression in breast cancer cells and enhances cisplatin chemosensitivity. Genes Cancer 2: 720-727, 2011.

11. Nakano K and Vousden KH: PUMA, a novel proapoptotic gene, is induced by p53. Mol Cell 7: 683-694, 2001.

12. McKenna DJ, McDade SS, Patel D and McCance DJ MicroRNA 203 expression in keratinocytes is dependent on regulation of p53 levels by E6. J Virol 84: 10644-10652, 2010.

13. Funamizu N, Lacy CR, Parpart ST, Takai A, Hiyoshi Y and Yanaga K: MicroRNA-301b promotes cell invasiveness through targeting TP63 in pancreatic carcinoma cells. Int J Oncol 44: 725-734, 2014.

14. Funamizu N, Lacy CR, Fujita K, Furukawa K, Misawa sT, Yanaga K and Manome Y: Tetrahydrouridine inhibits cell proliferation through cell cycle regulation regardless of cytidine deaminase expression levels. PLoS One 7: e37424, 2012.

15. Funamizu N, Kamata Y, Misawa T, Uwagawa T, Lacy CR, Yanaga $\mathrm{K}$ and Manome $\mathrm{Y}$ : Hydroxyurea decreases gemcitabine resistance in pancreatic carcinoma cells with highly expressed ribonucleotide reductase. Pancreas 41: 107-113, 2012.

16. Funamizu N, Okamoto A, Kamata Y, Misawa T, Uwagawa T, Gocho T, Yanaga K and Manome Y: Is the resistance of gemcitabine for pancreatic cancer settled only by overexpression of deoxycytidine kinase? Oncol Rep 23: 471-475, 2010.

17. Funamizu N1, Hu C, Lacy C, Schetter A, Zhang G, He P, Gaedcke J, Ghadimi MB, Ried T, Yfantis HG, et al: Macrophage migration inhibitory factor induces epithelial to mesenchymal transition, enhances tumor aggressiveness and predicts clinical outcome in resected pancreatic ductal adenocarcinoma. Int J Cancer 132: 785-794, 2013.

18. Li J, Zheng Y, Sun G and Xiong S: Restoration of miR-7 expression suppresses the growth of Lewis lung cancer cells by modulating epidermal growth factor receptor signaling. Oncol Rep 32: 2511-2516, 2014.

19. Liu Y, Zhou Y, Feng X, An P, Quan X, Wang H, Ye S, Yu C, He Y and Luo H: MicroRNA-126 functions as a tumor suppressor in colorectal cancer cells by targeting CXCR4 via the AKT and ERK1/2 signaling pathways. Int J Oncol 44: 203-210, 2014.

20. Bu P and Yang P: MicroRNA-203 inhibits malignant melanoma cell migration by targeting versican. Exp Ther Med 8: 309-315, 2014.

21. Tian L, Li M, Ge J, Guo Y, Sun Y, Liu M and Xiao H: MiR-203 is downregulated in laryngeal squamous cell carcinoma and can suppress proliferation and induce apoptosis of tumours. Tumour Biol 35: 5953-5963, 2014

22. Feber A, Xi L, Luketich JD, Pennathur A, Landreneau RJ, Wu M, Swanson SJ, Godfrey TE and Litle VR: MicroRNA expression profiles of esophageal cancer. J Thorac Cardiovasc Surg 135: 255-260, discussion 260, 2008.

23. Wei W, Wanjun L, Hui S, Dongyue C, Xinjun Y and Jisheng Z: miR-203 inhibits proliferation of HCC cells by targeting survivin. Cell Biochem Funct 31: 82-85, 2013.

24. Schetter AJ, Leung SY, Sohn JJ, Zanetti KA, Bowman ED, Yanaihara N, Yuen ST, Chan TL, Kwong DL, Au GK, et al: MicroRNA expression profiles associated with prognosis and therapeutic outcome in colon adenocarcinoma. JAMA 299: 425-436, 2008

25. Zhang Z, Zhang B, Li W, Fu L, Fu L, Zhu Z and Dong JT: Epigenetic silencing of miR-203 upregulates SNAI2 and contributes to the invasiveness of malignant breast cancer cells. Genes Cancer 2: 782-791, 2011.

26. Gottardo F, Liu CG, Ferracin M, Calin GA, Fassan M, Bassi P, Sevignani C, Byrne D, Negrini M, Pagano F, et al: Micro-RNA profiling in kidney and bladder cancers. Urol Oncol 25: 387-392, 2007.

27. Greither T, Grochola LF, Udelnow A, Lautenschläger C, Würl P and Taubert H: Elevated expression of microRNAs 155, 203, 210 and 222 in pancreatic tumors is associated with poorer survival. Int J Cancer 126: 73-80, 2010.

28. Ikenaga N, Ohuchida K, Mizumoto K, Yu J, Kayashima T, Sakai H, Fujita H, Nakata K and Tanaka M: MicroRNA-203 expression as a new prognostic marker of pancreatic adenocarcinoma. Ann Surg Oncol 17: 3120-3128, 2010.
29. Yang A, Kaghad M, Wang Y, Gillett E, Fleming MD, Dötsch V, Andrews NC, Caput D and McKeon F: p63, a p53 homolog at 3 q27-29, encodes multiple products with transactivating, death-inducing, and dominant-negative activities. Mol Cell 2: 305-316, 1998.

30. Yang A, Schweitzer R, Sun D, Kaghad M, Walker N, Bronson RT, Tabin C, Sharpe A, Caput D, Crum C, et al: p63 is essential for regenerative proliferation in limb, craniofacial and epithelial development. Nature 398: 714-718, 1999.

31. Yuan M, Luong P, Hudson C, Gudmundsdottir K and Basu S c-Abl phosphorylation of $\Delta \mathrm{Np} 63 \alpha$ is critical for cell viability. Cell Death Dis 1: e16, 2010.

32. Rinne T, Brunner HG and van Bokhoven H: p63-associated disorders. Cell Cycle 6: 262-268, 2007.

33. Yi R, Poy MN, Stoffel M and Fuchs E: A skin microRNA promotes differentiation by repressing 'stemness'. Nature 452: 225-229, 2008

34. Yuan Y, Zeng ZY, Liu XH, Gong DJ, Tao J, Cheng HZ and Huang SD: MicroRNA-203 inhibits cell proliferation by repressing $\triangle \mathrm{Np} 63$ expression in human esophageal squamous cell carcinoma. BMC Cancer 11: 57, 2011.

35. Suzuki HI, Yamagata K, Sugimoto K, Iwamoto T, Kato S and Miyazono K: Modulation of microRNA processing by $\mathrm{p} 53$. Nature 460: 529-533, 2009.

36. Hemann MT, Zilfou JT, Zhao Z, Burgess DJ, Hannon GJ and Lowe SW: Suppression of tumorigenesis by the p53 target PUMA. Proc Natl Acad Sci USA 101: 9333-9338, 2004.

37. Michalak EM, Villunger A, Adams JM and Strasser A: In several cell types tumour suppressor p53 induces apoptosis largely via Puma but Noxa can contribute. Cell Death Differ 15: 1019-1029, 2008.

38. Viticchiè G, Lena AM, Latina A, Formosa A, Gregersen LH, Lund AH, Bernardini S, Mauriello A, Miano R, Spagnoli LG, et al: MiR-203 controls proliferation, migration and invasive potential of prostate cancer cell lines. Cell Cycle 10: 1121-1131, 2011.

39. Miao L, Xiong X, Lin Y, Cheng Y, Lu J, Zhang J and Cheng N: miR-203 inhibits tumor cell migration and invasion via caveolin-1 in pancreatic cancer cells. Oncol Lett 7: 658-662, 2014.

40. Li J, Chen Y, Zhao J, Kong F and Zhang Y: miR-203 reverses chemoresistance in p53-mutated colon cancer cells through downregulation of Akt2 expression. Cancer Lett 304: 52-59, 2011.

41. Lena AM, Shalom-Feuerstein R, Rivetti di Val Cervo P, Aberdam D, Knight RA, Melino G and Candi E: miR-203 represses 'stemness' by repressing DeltaNp63. Cell Death Differ 15: 1187-1195, 2008.

42. Wellner U, Schubert J, Burk UC, Schmalhofer O, Zhu F, Sonntag A, Waldvogel B, Vannier C, Darling D, zur Hausen A, et al: The EMT-activator ZEB1 promotes tumorigenicity by repressing stemness-inhibiting microRNAs. Nat Cell Biol 11: $1487-1495,2009$.

43. Wang C, Zheng X, Shen C and Shi Y: MicroRNA-203 suppresses cell proliferation and migration by targeting BIRC5 and LASP1 in human triple-negative breast cancer cells. J Exp Clin Cancer Res 31: 58, 2012

44. Takeshita N, Mori M, Kano M, Hoshino I, Akutsu Y, Hanari N, Yoneyama Y, Ikeda N, Isozaki Y, Maruyama T, et al: miR-203 inhibits the migration and invasion of esophageal squamous cell carcinoma by regulating LASP1. Int J Oncol 41: 1653-1661, 2012.

45. Okumura T, Shimada Y, Moriyama M, Takei Y, Omura T, Sekine S, Nagata T, Shimizu K and Tsukada K: MicroRNA-203 inhibits the progression of esophageal squamous cell carcinoma with restored epithelial tissue architecture in vivo. Int J Oncol 44: 1923-1932, 2014.

46. He JH, Li YM, Li YG, Xie XY, Wang L, Chun SY and Cheng WJ: hsa-miR-203 enhances the sensitivity of leukemia cells to arsenic trioxide. Exp Ther Med 5: 1315-1321, 2013. 